\title{
Comparative performance in discrimination learning tasks in two New World primates (Saimiri sciureus and Callicebus moloch)
}

\author{
DOROTHY MUNKENBECK FRAGASZY \\ San Diego State University, San Diego, California 92182
}

\begin{abstract}
Squirrel monkeys (Saimiri sciureus) and titi monkeys (Callicebus moloch) were tested in three two-choice visual discrimination experiments. Although, on average, squirrel monkeys performed more accurately than titis, the range of response accuracies in the two species overlapped considerably in all three experiments and changes in response accuracy over test sessions and across experiments were similar in the two species. Thus, the species shared several behavioral characteristics expected of New World primates in this setting. Squirrel monkeys' performance appeared to be more affected than titis' by task difficulty, and squirrel monkeys were individually less consistent than titis. These differences were associated with higher activity levels and briefer overt attentiveness to the repetitive task in squirrel monkeys and, conversely, with lower activity levels, slower working speeds, and sustained interest in the task in titis. The associated differences are discussed in relation to each species performance in other laboratory settings and the characteristic patterns of foraging and use of space in nature.
\end{abstract}

This report concerns performance in laboratory learning tasks in two New World primate species, the squirrel monkey (Saimiri sciureus) and the titi monkey (Callicebus moloch). Previous research has suggested that, with the exception of Cebus species, learning skills do not vary markedly among New World primate species and the species-typical characteristics, such as activity level, docility, and inquisitiveness, may be responsible for much of the observed variations in performance (Devine, 1970; Polidora, 1964). One aim of this research was to compare the performance of titis and squirrel monkeys on equivalent learning tasks. This is the first report of titis' performance on traditional learning tasks. A second aim was to clarify the relationship between possible differences in performance and species-typical contrasts in behavior and ecology in the natural environment. An ecological perspective has proved useful in interpreting species-typical behavior in learning tasks in many species (Bolles, 1970; Hinde \& Stevenson-Hinde, 1973; Seligman \& Hager, 1972; Shettleworth, 1972). Comparative study of squirrel and titi monkeys was expected to suggest relationships between naturalistic behavior and performance on learning tasks that may be useful in other comparative studies of learning skills, especially with other New World primates.

Squirrel and titi monkeys both belong to the Cebidae. Both are small-bodied, omnivorous, diurnal, and arboreal; both have similar, well-developed sensory and motor skills; and both exploit similar forested habitats. But they differ markedly in several aspects of behavior in the wild. Squirrel monkeys are group-living and highly active, are thought to range widely, and tend toward insectivory (Baldwin \& Baldwin, 1971; Hladik \& Hladik, 1969; Thorington, 1967). Titis are monogamous, comparatively sedentary, territorial, and tend toward folivory (Kinzey, 1978, in press; Mason, 1966, 1968). Additionally, studies with these species have demonstrated marked behavioral differences in a variety of loosely structured captive situations, such as in a novel environment (Fragaszy, 1979), in a familiar environment (Mason, 1971, 1974), and while feeding or investigating novel objects in the home cage (Fragaszy, 1978a; Fragaszy \& Mason, 1978). These studies have identified behavioral characteristics which contribute to each species' behavior in nature (see Fragaszy, Note 1). In particular, squirrel monkeys are more active, more variable, and more opportunistic than titis in their use of space, locomotor habits, and feeding behavior. Titis are slower, are more consistent feeders and travelers, and are more dependent upon the presence and activities of an opposite-sex primate than are squirrel monkeys for the organization of routine daily activities.

Behavioral characteristics expressed in relatively unstructured tasks were expected to appear in the more constrained settings used in these studies, and furthermore, it was expected that they would influence performance on the learning task in a variety of ways. Specifically, although titis and squirrel monkeys were expected to achieve similar levels of correct discrimination performance (given their relatively close phylogenetic status), behavioral differences related to attention span, activity levels, and locomotor tendencies were expected to produce differences in the pattern of responding. For example, latency, reaction to 
wrong selections, and consistency of performance within and over test sessions were expected to vary between the species.

The experiments reported here investigated this possibility. The three experiments were scaled according to the number of discriminable dimensions available to the subject (Harlow, 1951; Polidora, 1966; Sutherland \& Mackintosh, 1971) in order to provide a range of performance comparisons (Polidora, 1967). Stimuli for the first experiment were "junk objects" for which at least color, brightness, size, shape, and texture varied between objects in a pair. In the second experiment, stimuli were planometric patterns which varied in color, contour, and brightness. This task was expected to be more difficult than junk-object discriminations. The third experiment presented a twodimensional discrimination problem (color and brightness). After training to criterion on the problem, a series of test trials were conducted in which the task was scaled according to the size of the color cue and, in consequence, the size of a white margin surrounding the cue. Thus, the size of cue and contiguity between cue and reward covaried. Discrimination of a smaller cue with larger white margin was expected to be more difficult than discrimination of a larger cue with a smaller margin (Polidora \& Fletcher, 1964; Polidora \& Thompson, 1964).

\section{METHODS}

\section{Design}

Experiments 1 and 2. Five problems were presented in each experiment. In each problem, two objects were to be discriminated from each other. Each subject completed two consecutive 25 trial sessions per problem. Correct discriminanda were matched over subjects, and problems were presented in balanced order. Within sessions, placement of reward and correct object followed a modified random order (Gellermann) series (Fragaszy \& Fragaszy, 1978).

Experiment 3. A color-brightness discrimination problem was scaled into five levels of difficulty based upon the total area covered by the color cue $(20 \%$ to $100 \%$ in $20 \%$ increments). Prior to testing on variable surface-area trials, subjects were trained to criterion on the basic red-green discrimination problem at the simplest level ( = Level $1,100 \%$ of the discriminanda's surface area colored). Correct color assignments were balanced over subjects.

Following pretraining, 10 daily test sessions were administered. A session consisted of one 5-trial block for each surface-area condition ( 25 trials per session). Order for conditions and leftright placement of the correct object were balanced over days and subject.

\section{Subjects}

Ten monkeys of each species served as subjects. The squirrel monkeys (five males and five females) were all adults. The titis included four adult males, five adult females, and one yearling female living with her parents. All subjects were housed in heterosexual pairs, or as a nuclear family group in the case of the titi family.

Nine of the squirrel monkeys and eight of the titis had had previous experience in the WGTA apparatus used in these experiments during food-preference studies (Fragaszy, 1978a), but none of the subjects had ever participated in a discriminationlearning experiment.

\section{Apparatus}

A modified Wisconsin General Testing Apparatus was used. It consisted of a restraining area $(35 \times 35 \times 45 \mathrm{~cm})$ that contained a wood perch $5 \mathrm{~cm}$ above the floor and a testing area of similar size that contained a retractable stimulus tray $(12 \mathrm{~cm}$ wide $\times 30 \mathrm{~cm}$ long). The stimulus tray was painted gray within semigloss enamel and contained two food wells spaced so that the nearer edges of the wells were $15 \mathrm{~cm}$ apart. The subject was separated from the testing area by an opaque sliding panel and vertical metal rods spaced $2.5 \mathrm{~cm}$ apart. The observer viewed the subject through a one-way screen. Two $25-\mathrm{W}$ bulbs, centered $30 \mathrm{~cm}$ over the stimulus tray and $18 \mathrm{~cm}$ above the subject's area, enhanced the subject's visibility. A foot-operated electric timer (accurate to $.01 \mathrm{sec}$ ) was available. Testing occurred in a building adjacent to the living areas.

The discriminanda used in these experiments are described in detail in Fragaszy (1978b). Briefly, the junk objects in Experiment 1 were common small items mounted on flat, wooden bases of irregular shape (for example, a wooden spool, painted red, on a purple base, or a metal hook mounted on a silver base). Each member of an object pair had a differently colored base. Discriminanda in Experiment 2 were drawings made with wax crayons on $6.4 \times 7.6 \mathrm{~cm}$ rectangles of white paper. Each member of a stimulus pair varied distinctly from the other in color and pattern. For example, one pair consisted of one drawing of orange vertical stripes with a brown horizontal strip at the bottom and one drawing of circles on a white background. The drawings were pasted onto the top surface of wooden blocks of equal dimensions. The blocks were $3.8 \mathrm{~cm}$ thick at the back; their top surfaces sloped toward the subject at approximately a $20-\mathrm{deg}$ angle. The blocks were encased in impermeable transparent plastic for easy cleaning.

Discriminanda in Experiment 3 were squares of poster paper that were painted bright red or green with high-gloss enamel and pasted onto $5.1 \times 6.4 \mathrm{~cm}$ rectangles of white poster paper. The colored and white cues were centered on the top surface of 5.1 $\times 6.4 \mathrm{~cm}$ wooden blocks, the top surfaces of which sloped toward the subject at an angle of approximately $20 \mathrm{deg}$. Five sets of colored stimuli were used, ranging from $100 \%$ colored (Level 1) to $20 \%$ colored (Level 5 ). The blocks were encased in impermeable transparent plastic for easy cleaning.

Rewards were small (approximately $6 \mathrm{~cm}^{3}$ ) pieces of preferred foods: raisin, marshmallow, grape, orange, apple, banana, tomato, hamburger, cheese, and peanut.

\section{Procedures}

Test procedures were identical in Experiments 1 and 2. Each subject was shaped in the task, using the procedure described by Woodburne (1965), until it consistently uncovered, within $30 \mathrm{sec}$, the food hidden under an unpainted wood block. Shaping was followed by extensive practice with five junk-object problems ( 50 trials on each problem) before Experiment 1 was begun. Thereafter, each subject received a single daily test session on one problem for 2 consecutive test days, for a total of 50 trials per problem. In Experiment 1, if a subject consistently avoided a correct discriminandum (i.e., made 15 consecutive wrong responses in one session), a new problem was substituted. This occurred in one titi and in two squirrel monkeys. Testing occurred prior to daily feeding. Pairmates were not tested consecutively.

Test sessions began with four "warm-up" trials (two lefts, two rights) with a single unpainted wood block. Thus, each subject was "primed" before test trials began, a procedure recommended by Rumbaugh (1969).

Before each trial the correct object was placed over the baited well. The subject's panel was raised, and the tray was pushed toward the subject. A foot-operated timer was activated when the tray reached the full forward position. The timer was stopped upon first displacement of an object. As soon as a well was uncovered (and the food taken, if the choice was correct), the tray was withdrawn. At the end of timing, choice of object and response latency (to the nearest whole second) were noted. No choice within $30 \mathrm{sec}$ was scored as a "balk"; no latency score was 
earned in a balk trial. (Frequency of balks was analyzed separately from latency data.) Another trial was prepared as soon as the subject had consumed the food reward, in the case of a correct choice, or within about $15 \mathrm{sec}$ in the case of an incorrect choice of a balk. Trials that terminated in balks were repeated at the end of regular testing each day, or in another test session if the subject balked on four consecutive trials.

In Experiment 3, the subjects were trained with Level 1 blocks $(100 \%$ surface area colored). Each subject completed at least two training sessions and met a performance criterion of 23 correct responses in one 25-trial session. After meeting this criterion, the subjects were given one additional "practice" session with the $100 \%$ colored blocks before beginning daily test sessions.

Trial procedures were the same as in Experiments 1 and 2 except in the case of balks. Balks were made up at the conclusion of each 5-trial block at a particular level, rather than at the end of the session. Incomplete sessions were made up in 5trial blocks at each level at the conclusion of regularly scheduled test sessions.

Interobserver reliability for latency scores was assessed by comparing total latencies for each of several 25 -trial sessions simultaneously scored by two independent observers. A minimal agreement of $90 \%$ (calculated as smaller sum $\div$ larger sum) between observers on each session was required prior to the start of test sessions.

\section{Analysis}

Data from each experiment were tabulated by blocks within problems for each subject, and then subjected to a mixed-model analysis of variance. Main effects in Experiments 1 and 2 were species, 10-trial block, and problem order; in Experiment 3 they were species, 5-trial block, and level of surface area. Other statistical procedures were applied to the data when appropriate. Chance levels of individual performance per problem were calculated to be $<64 \%$ correct, using a one-sample chi-square test. A two-tailed $\alpha$ of .05 was used throughout for determinations of significance.

\section{QUANTITATIVE RESULTS}

\section{Experiment 1}

None of the junk-object problems was difficult for a majority of subjects in either species. Levels of correct choice were significantly better than chance on two or more problems for all titis and on four or more problems for all squirrel monkeys (see Figure 1). Analysis of variance of choice data revealed significant species and blocks main effects. Within-problem performance of both species improved over the five 10trial blocks per problem, and squirrel monkeys made significantly more correct choices than did titis. The difference between the species was significant ( $t$ test) for every 10-trial block except the first. However, titis had not yet reached peak performance levels after 40 trials. A Wilcoxon test on data from the nine titis which had not attained a perfect score on Block 4 indicated that their scores improved significantly from Block 4 to Block $5[T(9)=4, p<.05]$. In comparison, the squirrel monkeys' performance in these blocks was stable (see Figure 2).

Analysis of latency data revealed significant main effects for species and problem order. Squirrel monkeys responded more quickly than titis and balked significantly less often $[\mathrm{t}(18)=5.82, \mathrm{p}<.001$; see Figure 1]. Both species responded more quickly as
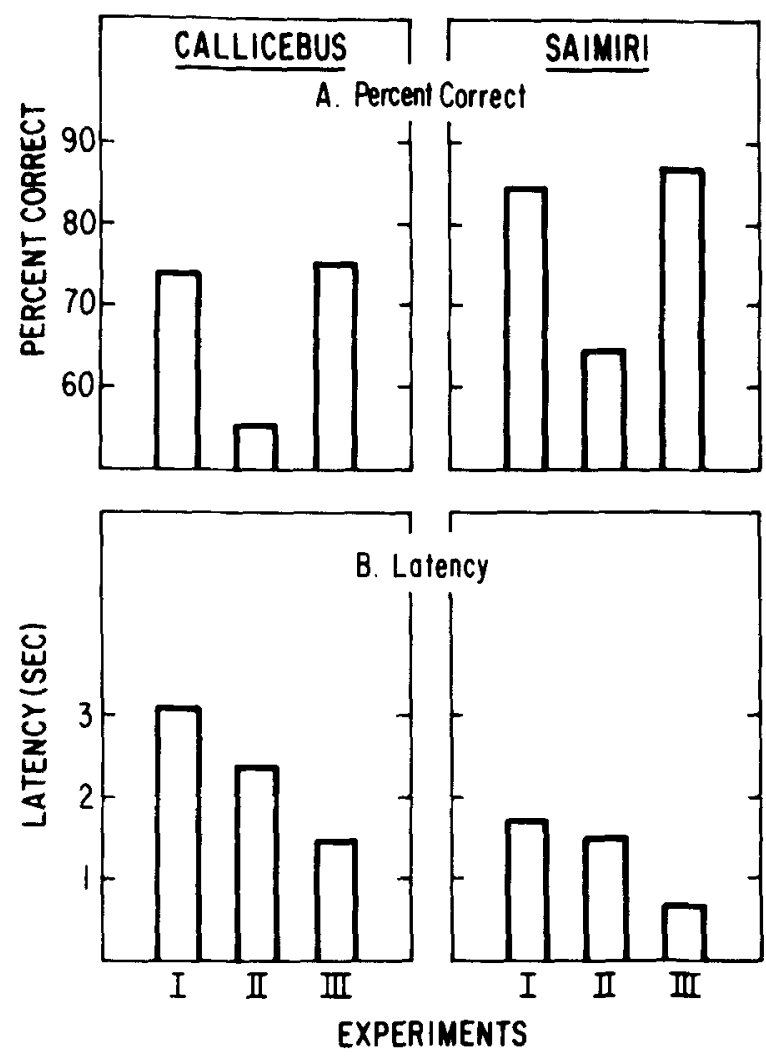

Figure 1. Percentage of correct response (A) and mean latency (B) in Experiments 1, 2, and 3.

testing progressed (see Table 1). For example, mean latencies were $3.6 \mathrm{sec}$ on the first problem and $2.7 \mathrm{sec}$ on the fifth problem in titis; comparable scores for squirrel monkeys were 2.3 and $1.1 \mathrm{sec}$.

\section{Experiment 2}

Planometric discriminations were more difficult than object discriminations for both species. Correct responses declined from an average of $74 \%$ to $56 \%$ for titis and from $84 \%$ to $62 \%$ for squirrel monkeys [dependent ts $(9)=6.26$ for titis and 6.74 for squirrel monkeys, $p<.001$, both cases; see Figure 1]. Nevertheless, response accuracy improved over blocks in both species, providing the only significant effect in ANOVA for this variable (see Figure 2 and Table 2).

The slight difference between species in overall percentage of correct response was not significant, in contrast with the findings of Experiment 1. Moreover, no significant species effects were found in latency data (see Table 2). The titis' latencies were significantly lower in Experiment 2 than in Experiment 1 [dependent $\mathrm{t}(9)=2.68, \mathrm{p}<.05$ ]; the squirrel monkeys' scores were not significantly different in the two experimients.

Data on balking suggest that the species were affected differently by the difficulty of the task in Experiment 2. For example, squirrel monkeys balked more often in Experiment 2 than in Experiment 1, but titis did not $\left[\chi^{2}(1)=4.13, p<.05\right]$. The pattern of balking over problems was also different in the 
species. Titis balked less often on later problems than on earlier problems, whereas squirrel monkeys balked less often on earlier problems than later ones. A chisquare test demonstrated a significant difference in distribution of balks between Problems 1 and 5 in both species $\left[\chi^{2}(1)=33.4, \mathrm{p}<.001\right]$. Thus, even
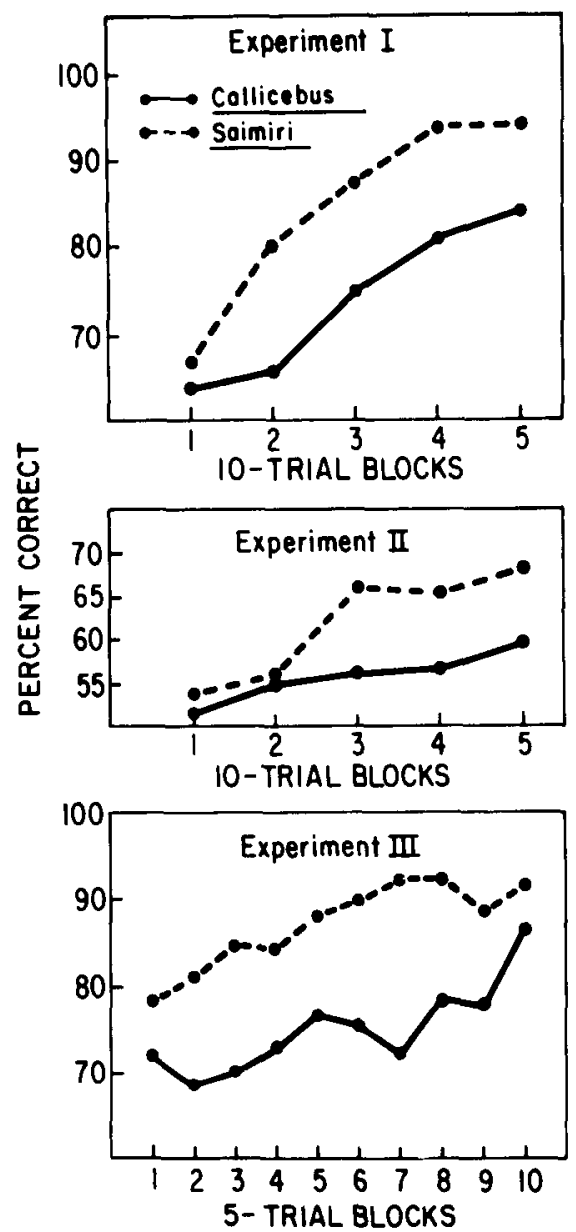

Figure 2. Percentage of correct response over block in each experiment. Note that in Experiments 1 and 2 blocks consist of 10 trials and that in Experiment 3 blocks consist of five trials and represent sequential trials over 10 test sessions. though the task was at least as difficult for titis as it was for squirrel monkeys, titis did not balk more often on the more difficult task than they did on an easier task (Experiment 1), and they balked less often after extensive testing. Squirrel monkeys, however, became increasingly unresponsive as testing progressed, and balked more often than when the task was easier.

A second indication that squirrel monkeys were more affected than were titis by the increased difficulty of the task in Experiment 2 is found in the consistency of individual rankings on percentage of correct responses. Titis' rankings changed less between experiments than did squirrel monkeys'. The correlation between percentage of correct responses in Experiments 1 and 2 was moderately high for titis $\left(r_{x y}=.598, p<.10\right)$. In contrast, the correlation for the squirrel monkeys' scores was much weaker $\left(r_{x y}\right.$ $=+.091$ ). In fact, the monkey ranked first in Experiment 1 shifted to 10th place in Experiment 2.

\section{Experiment 3}

In both species, overall levels of choice performance in Experiment 3 were comparable to the levels in Experiment 1 (see Figure 1). As in Experiment 1, the squirrel monkeys' performance levels were higher than the titis', producing a significant main effect for species (see Table 3). The magnitude of the difference between the species was similar to that found in Experiment 1 , and was much larger than the (nonsignificant) difference in Experiment 2.

Both block and level were significant sources of variation in performance levels. The performance of both species improved over blocks (i.e., test sessions) and as the amount of colored surface area increased (see Figures 2 and 3 and Table 3). But variation over levels of the amount of colored surface was uneven in the two species, producing a significant Species by Level interaction (see Figure 3 and Table 3). The absolute magnitude of the decline in performance between Level 1 and Level 5 was somewhat larger in squirrel monkeys than in titis, although not significantly so ( $t$ test). A second factor contributing to the

Table 1

Analysis of Variance, Experiment 1

\begin{tabular}{|c|c|c|c|c|c|}
\hline \multirow[b]{2}{*}{ Source } & \multirow[b]{2}{*}{$\mathrm{df}$} & \multicolumn{2}{|c|}{ Number Correct } & \multicolumn{2}{|c|}{ Latency } \\
\hline & & MSe & $\mathbf{F}$ & MSe & $\mathbf{F}$ \\
\hline Species & 1 & 133.13 & $6.165^{*}$ & $25,063.20$ & $7.006^{*}$ \\
\hline Subject & 18 & 21.59 & & $3,577.30$ & \\
\hline Problem Order & 4 & 4.01 & $.636 \dagger$ & $2,269.22$ & $2.633^{*}$ \\
\hline Species by Problem Order & 4 & 4.13 & $.655 t$ & $1,106.48$ & $1.284 \dagger$ \\
\hline Subject by Problem Order & 72 & 6.30 & & 861.92 & \\
\hline Block & 4 & 100.84 & $37.508^{* *}$ & 504.41 & $1.227 \dagger$ \\
\hline Species by Block & 4 & 5.18 & $1.928 \dagger$ & 169.14 & $.411 \dagger$ \\
\hline Subject by Block & 72 & 2.69 & & 411.04 & \\
\hline Problem Order by Block & 16 & 2.11 & $1.157 \dagger$ & 415.16 & $1.119 \dagger$ \\
\hline Species by Problem Order by Block & 16 & 1.60 & $.874 \dagger$ & 345.07 & $.996 \dagger$ \\
\hline Subject by Problem Order by Block & 288 & 1.83 & & 346.39 & \\
\hline
\end{tabular}

${ }^{*} p<.05 . \quad{ }^{*} p<.001 . \quad$ TNonsignificant. 
Table 2

Analysis of Variance, Experiment 2

\begin{tabular}{|c|c|c|c|c|c|}
\hline \multirow[b]{2}{*}{ Source } & \multirow[b]{2}{*}{$\mathrm{df}$} & \multicolumn{2}{|c|}{ Number Correct } & \multicolumn{2}{|c|}{ Latency } \\
\hline & & MSe & $\mathrm{F}$ & MSe & $\mathrm{F}$ \\
\hline Species & 1 & 47.43 & $3.008+$ & $14,905.80$ & $3.679+$ \\
\hline Subject & 18 & 15.77 & & $4,051.76$ & \\
\hline Problem Order & 4 & 7.83 & $1.090 \dagger$ & $1,308.74$ & $1.911^{\dagger}$ \\
\hline Species by Problem Order & 4 & 9.60 & $1.337 \dagger$ & $1,368.52$ & $1.999+$ \\
\hline Subject by Problem Order & 72 & 7.18 & & 684.76 & \\
\hline Block & 4 & 21.57 & $7.468^{*}$ & 95.57 & $.424 \dagger$ \\
\hline Species by Block & 4 & 4.07 & $1.408+$ & 454.37 & $2.017+$ \\
\hline Subject by Block & 72 & 2.88 & & 225.22 & \\
\hline Problem Order by Block & 16 & 2.433 & $1.295 \dagger$ & 307.70 & $1.591 \dagger$ \\
\hline Species by Problem Order by Block & 16 & 1.69 & $.901+$ & 165.66 & $.857 \dagger$ \\
\hline Subject by Problem Order by Block & 288 & 1.88 & & 193.34 & \\
\hline
\end{tabular}

${ }^{*} p<.001$. †Nonsignificant.

Table 3

Analysis of Variance, Experiment 3

\begin{tabular}{|c|c|c|c|c|c|}
\hline \multirow[b]{2}{*}{ Source } & \multirow[b]{2}{*}{ df } & \multicolumn{2}{|c|}{ Number Correct } & \multicolumn{2}{|c|}{ Latency } \\
\hline & & MSe & $\mathbf{F}$ & MSe & $\mathrm{F}$ \\
\hline Species & 1 & 88.21 & $8.422 * *$ & $3,549.46$ & $5.313^{*}$ \\
\hline Subject & 18 & 10.47 & & 668.02 & \\
\hline Level & 4 & 5.84 & $6.213+$ & 15.54 & $.236 \dagger+$ \\
\hline Species by Level & 4 & 2.61 & $2.774^{*}$ & 33.35 & $.506+\dagger$ \\
\hline Subject by Level & 72 & .94 & & 69.96 & \\
\hline Block & 9 & 5.01 & $5.357 \dagger$ & 117.26 & $1.324 \dagger \dagger$ \\
\hline Species by Block & 9 & 1.14 & $1.219+\dagger$ & 80.76 & $.912 \dagger \dagger$ \\
\hline Subject by Block & 162 & .94 & & 88.59 & \\
\hline Level by Block & 36 & 1.15 & $1.664 * *$ & 18.71 & $.502 \div \dagger$ \\
\hline Species by Level by Block & 36 & .81 & $1.163 t \dagger$ & 27.70 & $.743+t$ \\
\hline Subject by Level by Block & 648 & .69 & & 37.27 & \\
\hline
\end{tabular}

${ }^{*} p<.05 . \quad{ }^{*} p<.01 . \quad \dagger p<.001 . \quad+$ tNonsignificant.

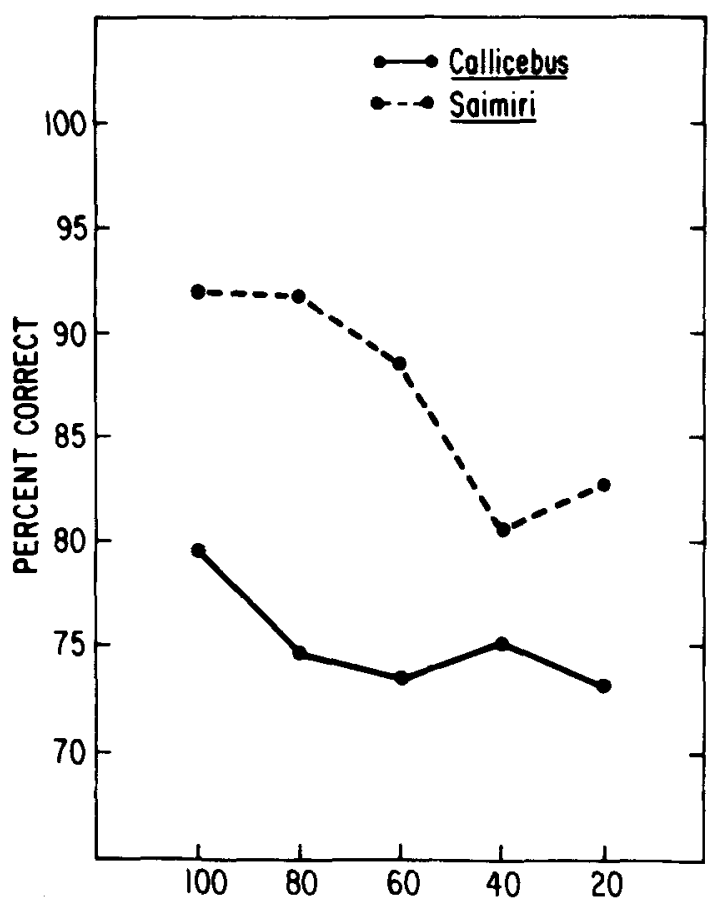

Figure 3. Percentage of correct response in a color-discrimination task (Experiment 3) at five levels of surface area coverage. observed interaction is that the maximum difference between two levels occurred at different levels in the two species. Nevertheless, the overall trend in performance was similar in the two species. Thus, variation in cue size and/or reward contiguity affected both species' performance similarly, despite differences between them in absolute frequency of correct response. A significant interaction also occurred between block and level. Improvement over blocks was greatest on the most difficult levels: The titis' scores rose from $58 \%$ to $82 \%$ correct, Blocks 1 to 10 , on Level 5 , but only from $72 \%$ to $84 \%$ on Level 1 . The squirrel monkeys' scores were $62 \%$, Block 1 , vs. $86 \%$, Block 10, on Level 5, and $88 \%$, Block 1, vs. $96 \%$, Block 10, on Level 1.

As in the two previous experiments, latencies were lower in squirrel monkeys than in titis (see Figure 1 and Table 3 ). Both species responded more quickly in Experiment 3 than in the two previous experiments: All comparisons were significant (dependent $t$ test) except that between Experiments 2 and 3 for squirrel monkeys. However, despite the differences in choice accuracy among the five levels in both species, latencies did not vary systematically over levels in either species. 
It is interesting to note that performance on the last session (Block 10, combined levels) was not significantly different in the two species (see Figure 2). This suggests that titis acquired correct responses at slower rates than squirrel monkeys, but that they were capable of achieving equally high terminal levels of performance accuracy. Further evidence to support the view that titis were "slow learners" is the finding that these monkeys required an average of 6.7 initial training sessions to reach performance criterion on the red-green discrimination task, as compared with 4.3 sessions for squirrel monkeys $[\mathrm{t}(16)=2.60, \mathrm{p}<.02]$ (data from one subject of each species were excluded because each had had several sessions of less than 25 trials).

\section{Interexperiment Comparisons}

Interexperiment comparisons of performance accuracy and response latency indicate that the titis' behavior was more consistent than the squirrel monkeys'. Titis' individual performance levels were moderately consistent over experiments, as indicated by the positive correlations between performance accuracy in all comparisons $\left(\mathrm{r}_{\mathrm{xy}}=+.598\right.$, Experiments $1-2$; +.342 , Experiments $1-3$; and +.402 , Experiments 2-3). However, performance levels of individual squirrel monkeys varied widely across experiments, as indicated by the lack of correlation between performance levels in different experiments $\left(r_{x y}=+.091\right.$, Experiments 1-2; -.085 , Experiments 1-3; and +.059 , Experiments 2-3). Similarly, the decline in latency over experiment, although apparent in both species (see Figure 1), was more consistent in titis. This is indicated by statistical significance in all comparisons for titis but nonsignificant differences between latencies in Experiments 1-3 and 2-3 for squirrel monkeys. And, even though the task in Experiment 3 was apparently more difficult for titis than it was for squirrel monkeys, titis balked significantly less often in this experiment than in the previous two [sign test $(9$ or 10$)$, $\mathrm{x}=1, \mathrm{p}<.04$, both cases]. Recall that the color discrimination task remained the same over test days in Experiment 3, whereas several different object sets were presented in each of the previous experiments. Thus, continued exposure to the same task was associated with less frequent balking than was observed when new problems were presented. This was not true of squirrel monkeys, however. Of the eight subjects which scored balks, four balked as often in Experiment 1 as in (or more often in Experiment 1 than in) Experiment 3.

\section{DISCUSSION}

These data provide the first information on discrimination performance in Callicebus, a primate genus which has not previously been used in laboratory studies of learning. Although, in general, squirrel monkeys performed more accurately than titis, the titis' individual response accuracies overlapped considerably with the squirrel monkeys' and terminal levels of performance did not differ between them in Experiment 3 (the experiment in which the most exposures to the same problem occurred). Response accuracy was similarly affected in both species by different levels of task difficulty, and both species responded more quickly as testing progressed. In short, the species performed similarly on several aspects of the task.

However, squirrel and titi monkeys' behavior in these experiments differed in several other dimensions. Overall, squirrel monkeys responded more quickly and balked less often than titis. On the other hand, squirrel monkeys balked more often on the most difficult tasks (in Experiment 2) than on the easier tasks. Titis were more consistent over experiments in this regard, responding significantly more quickly on each successive experiment. Titis were also individually more consistent in performance accuracy: correlations between individual performances across experiments were moderately positive for titis, averaging +.447 . Squirrel monkeys' scores were not correlated in the same comparisons. In summary, squirrel monkeys appeared more affected than titis by task difficulty, and their performance was more variable overall than the titis'.

Descriptive notes made during testing indicate several behavioral differences between the species associated with the findings noted above. Squirrel monkeys were generally more active and more variable than titis during testing. Although they seemed at ease in the test situation and usually responded quickly, the squirrel monkeys' attention to the task often wandered. In some cases, the monkeys' interest shifted from food to the discriminanda. Many subjects persistently manipulated the objects and blocks disregarding the food reward while they tried to pull the object through the bars and into the restraining cage. In addition to their manipulatory activities, they were variable in locomotor patterns. Squirrel monkeys frequently moved around the test cage and adopted a variety of postures during testing.

The titis' behavior differed from squirrel monkeys' in nearly every aspect mentioned above. One obvious contrast was that titis were much slower than squirrel monkeys at moving objects (see also Welles, 1973). But, in addition to displacing the blocks more slowly, titis moved toward the blocks more slowly. The choice process as a whole was markedly slower. Similar findings of slow choice behavior in titis have been obtained on tasks requiring only ordinary locomotion (Fragaszy, 1980), suggesting that the latency difference between the species observed in these experiments is not due simply to differences in prehensile skills.

There were strong indications that titis adjusted to the testing situation more slowly than squirrel monkeys. As testing progressed, the frequency and intensity of 
vocalizations in titis decreased, they consumed food rewards more consistently, and in general they appeared calmer and more engaged in the task. On the other hand, although titis were slower to begin working at the task than squirrel monkeys, once started, they worked more steadily, especially after several incorrect responses. Continued interest in the task was indicated by the titis' quiet postures in front of the stimulus tray during testing and by their sustained interest in the food reward throughout each session. In contrast, squirrel monkeys quickly reached peak response speeds, and the variability in their behavior appeared to be more a function of distraction than of lack of habituation to the test situation.

These findings are in accord with descriptions of each species' behavior in other laboratory studies. Squirrel monkeys are consistently more active than titis in the home cage and in various unfamiliar settings (Fragaszy, 1978b; Fragaszy \& Mason, 1978; Mason, 1971, 1974). They respond more quickly than titis in tasks requiring selection of specific alternatives, such as choosing a food item or a travel path (Fragaszy, 1978a, 1980). They are less distressed by separation from a familiar cagemate than are titis (Cubicciotti \& Mason, 1975), which may facilitate habituation to the test procedures in comparison with titis. Squirrel monkeys typically exhibit greater behavioral variability, within and across individuals, in motor actions and food preferences than do titis (Fragaszy, 1979, and unpublished data), and they tend to lose interest more quickly in repetitive tasks and unvaried foods (Fragaszy, 1978a, 1980). All these behavioral characteristics were evident in their performance in the learning tasks reported here, and they are consistent with their behavior in natural environments, in which much of their waking time is spent foraging actively for small, mobile insect prey (Baldwin \& Baldwin, 1972; Thorington, 1967, 1968). This mode of foraging probably involves nearly constant movement, quick manual capture behaviors, rapid adjustment to novel situations, and interest in varied objects (Fragaszy, Note 1).

The titis' lower levels of motor activity, greater behavioral consistency, and sustained interest in repetitive tasks are expected correlates of a sedentary, frugivorous-folivorous life-style in which habitual patterns of moving and feeding predominate. A second relationship between the titis' performance on these tasks and their behavior in other settings concerns the slow speed of titis' manual responses. This characteristic is most clearly relevant to feeding habits. Of course, stationary plant foods do not require rapid capture. But even the small component of insect protein in the titis' diets is probably obtained in a slow manner. Kinzey (1976) reports that a closely related species, Callicebus torquatus, used a slow stalking pattern to find and capture insects, in contrast with squirrel monkeys' rapid grabbing of jumping and flying insects. Slow manual responses to visible food items have been reported in laboratory studies with $C$. moloch as well (Fragaszy, 1978a).

It must be pointed out that the titis' slower acquisition of correct responses in the discrimination tasks in comparison with the squirrel monkeys' contrasts with their superior performance on other two-choice tasks requiring the use of visual cues (Fragaszy, 1980). It is apparent from those studies, and suggested by food choice studies (Fragaszy, 1978a), that titis are equally capable of accurate visual discriminations as squirrel monkeys. Thus, species differences in comparative response accuracy in the discrimination tasks used here should not be viewed as strong evidence that squirrel monkeys learn discrimination tasks in general more quickly or more accurately than titis. A variety of psychological factors, such as interest in obtaining the goal item and assessment of costs of an incorrect response undoubtedly contributed to differential performance accuracy in the two species over tasks (see Fragaszy, 1980, for discussion). It is clear that further work on species characteristics of task assessment are necessary to refine our conceptions of learning skills in New World primates.

In summary, squirrel monkeys apparently approached the discrimination tasks in a manner different from that of titis. It was suggested that major differences in behavioral ecology in these two species, namely, foraging and use of space, are meaningfully related to the differences in performance on the arbitrary tasks used in this research. An alternative explanation, that phylogenetic factors are responsible for performance differences in squirrel and titi monkeys, cannot be ruled out on the basis of these findings. Further comparative work with other New World primate species will help to determine the relative contributions of phylogeny and ecology to task performance. One might predict, on ecological grounds, that other New World high-activity-level monkeys that forage intensively on mobile insects (i.e., marmosets and tamarins) would exhibit performance similar to the squirrel monkeys', whereas more sedentary, frugivorous-folivorous feeders (such as howler monkeys) would share characteristics of response speed and consistency with titis. These predictions differ from those based on the consideration of phylogenetic relatedness alone. Comparison between squirrel monkeys and the Old World talapoins (Miopithecus talapoin), which are thought to be ecologically and behaviorally similar to squirrel monkeys (Rowell, 1973), is another possible means of assessing the importance of ecological factors. A phylogenetically distant but ecologically similar comparison group for titis is not as readily available, although the monogamous Mentawi langur (Presbytis potenzian $i$ ) is one possibility (Tilson \& Tenaza, 1976). 


\section{REFERENCE NOTE}

1. Fragaszy, D. M. Comparative studies of Saimiri and Callicebus: The expression of behavioral predispositions in social behavior. In D. M. Fragaszy \& J. Vogt, J. Field and laboratory studies of social behavior in New World primates. Book in preparation, 1980.

\section{REFERENCES}

Baldwin, J. D., \& Baldwin, J. I. Squirrel monkeys (Saimiri) in natural habitats in Panama, Colombia, Brazil, and Peru. Primates, 1971, 12, 45-61.

Baldwin, J. D., \& Baldwin, J. I. The ecology and behavior of squirrel monkeys (Saimiri oerstedii) in a natural forest in Western Panama. Folia Primatologica, 1972, 18, 161-184.

Bolles, R. C. Species-specific defense reactions and avoidance learning. Psychological Review, 1970, 71, 32-48.

Cubicciotti, D., III, \& Mason, W. A. Comparative studies of social behavior in Callicebus and Saimiri: Male-female emotional attachments. Behavioral Biology, 1975, 16, 185-197.

Devine, J. V. Stimulus attributes and training procedures in learning-set formation of rhesus and cebus monkeys. Journal of Comparative and Physiological Psychology, 1970, 73, 62-67.

Fragaszy, D. M. Contrasts in feeding behavior in squirrel and titi monkeys. In D. C. Chivers (Ed.), Recent advances in primatology (Vol. 1) Behaviour. London: Academic Press, 1978. (a)

Fragaszy, D. M. Comparative studies of visuo-spatial performance squirrel monkeys (Saimiri) and titi monkeys (Callicebus) (Doctoral dissertation, University of California, Davis, 1978). Dissertation Abstracts International, 1978, 39, 3038B. (University Microfilms No. 78-22, 643). (b)

Fragaszy, D. M. Squirrel and titi monkeys in a novel environment. In J. Erwin, T. Maple, \& G. Mitchell (Eds.), Captivity and behavior. New York: Van Nostrand, 1979.

Fragaszy, D. M. Comparative studies of squirrel monkeys (Saimiri) and titi monkeys (Callicebus) in travel tasks. Zeitschrift für Tierpsychologie, 1980, 54, 1-36.

Fragaszy, D. M., \& Mason, W. A. Response to novelty in Saimiri and Callicebus: Influence of social context. Primates, 1978, 19, 311-331.

Fragaszy, R. J., \& Fragaszy, D. M. A program to generate Gellermann (pseudorandom) series of binary states. Behavioral Research Methods \& Instrumentation, 1978, 10, 83-88.

Harlow, H. F. Primate learning. In C. P. Stone (Ed.), Comparative psychology. New York: Prentice-Hall, 1951.

Hinde, R. A., \& Stevenson-Hinde, J. Constraints on learning. New York: Academic Press, 1973.

HLaDik, A., \& Hladik, C. M. Rapports trophiques entre vegetation et primates dans la forêt de Barro Colorado (Panama). Terre et Vie, 1969, 1, 25-117.

Kinzey, W. G. Positional behavior and ecology in Callicebus torquatus. Yearbook of Physical Anthropology, 1976, 20, 468-480.

KINZEY, W. G. Feeding behaviour and molar features in two species of titi monkey. In D. C. Chivers (Ed.), Recent advances in primatology (Vol. 1) Behaviour. London: Academic Press, 1978.

KinzeY, W. G. Callicebus. In R. A. Mittermeier \& A. F. CoimbraFilho (Eds.), New World primatology. Rio de Janeiro: Brazilian Academy of Sciences, in press.
Mason, W. A. Social organization of the South American monkey, Callicebus moloch: A preliminary report. Tulane Studies in Zoology, 1966, 13, 23-28.

Mason, W. A. Use of space by Callicebus groups. In P. Jay (Ed.), Primates: Field studies in adaptation and variability. New York: Holt, Rinehart \& Winston, 1968.

Mason, W. A. Field and laboratory studies of social organization in Saimiri and Callicebus. In L. A. Rosenblum (Ed.), Primate behavior: Developments in field and laboratory research. New York: Academic Press, 1971.

Mason, W. A. Comparative studies of social behavior in Callicebus and Saimiri: Behavior of male-female pairs. Folia Primatologica, 1974, $22,1-8$.

Polidora, V. J. Learning abilities of New World monkeys. American Journal of Physical Anthropology, 1964, 22, 245-252.

Polidora, V. J. Visual pattern discrimination problems scaled for discriminative difficulty. In D. Starck, R. Schneider, \& H.-J Kuhn (Eds.), Progress in primatology. Stuttgart: Gustave Fischer Verlag, 1967.

Polidora, V. J. Stimulus correlates of visual pattern discrimination by monkeys: Multidimensional analyses. Perception \& Psychophysics, 1966, 1, 405-414.

Polidora, V. J., \& Fletcher, H. J. An analysis of the importance of S-R spatial contiguity for proficient primate discrimination performance. Journal of Comparative and Physiological Psychology, 1964, 57, 224-230.

Polidora, V. J., \& Thompson, W. J. Stimulus correlates of visual pattern discrimination by monkeys: Area and contour. Journal of Comparative and Physiological Psychology, 1964, 57, 264-269.

RoweLL, T. E. Social organization of wild talapoin monkeys. American Journal of Physical Anthropology, 1973, 38, 593-597.

Rumbaugh, D. M. Learning and sensory capacities of the squirrel monkey in phylogenetic perspective. In L. A. Rosenblum \& R. W. Cooper (Eds.), The squirrel monkey. New York: Academic Press, 1968.

Seligman, M. E. P., \& Hager, J. S. The biological boundaries of learning. New York: Appleton, 1972.

Shetrteworth, S. J. Constraints on learning. In D. S. Lehrman, R. A. Hinde, \& E. Shaw (Eds.), Advances in the study of behavior (Vol. 4). New York: Academic Press, 1972.

Suthe RLAND, N. S., \& Mackintosh, N. J. Mechanisms of animal discrimination learning. New York: Academic Press, 1971.

Thorington, R. W. Feeding and acitivty of Cebus and Saimiri in a Colombian forest. In D. Starck, R. Schneider, \& H.-J. Kuhn (Eds.), Progress in primatology. Stuttgart: Gustav Fischer Verlag, 1967.

Thorington, R. W. Observations of squirrel monkeys in a Colombian forest. In L. A. Rosenblum \& R. W. Cooper (Eds.), The squirrel monkey. New York: Academic Press, 1968.

Tilson, R. C., \& Tenaza, R. R. Monogamy and duetting in an Old World monkey. Nature, 1976, 263, 320-321.

WELLes, J. F. The anthropoid hand: A comparative study of prehension (Doctoral dissertation, Tulane University, 1973). Dissertation Abstracts International, 1973, 34, 1890B. (University Microfilms No. 73-25, 309).

Woodburne, L. S. Visual acuity of Saimiri sciureus. Psychonomic Science, 1965, 3, 307-308.

(Received for publication April 16, 1980; revision accepted June 23, 1980.) 